\title{
O DESAFIO DA ATUAÇÃO DO ENFERMEIRO FRENTE A AUSÊNCIA PATERNA NO ACOMPANHAMENTO PRÉ-NATAL: ESTRATÉGIAS E INTERVENÇÕES
}

\author{
Matheus Gutterres Silva Ladeira ${ }^{1}$ \\ João Pedro Ribeiro Serrano ${ }^{2}$ \\ Fabíola Vargas Apolinário ${ }^{3}$
}

RESUMO: Incluir a figura paterna nos cuidados pertinentes ao ciclo gravídico é um desafio, já que o mesmo é visto como uma responsabilidade materna e poucos serviços de saúde promovem a integração paterna. A gestação é um momento único onde a participação do pai encoraja a mãe e desenvolve e promove o vínculo com o filho desde a vida uterina. Dado sua importância a compreender os motivos que promovem a ausência dos pais nos cuidados prénatal proporcionará ao enfermeiro traçar estratégias para reverter esse quadro e para conseguir atingir esses objetivos, a pesquisa foi realizada através de uma revisão bibliográfica sistemática, sendo selecionados 17 artigos científico sobre a temática, a pesquisa foi realizada no período de abril a novembro de 202I.

Palavras-chave: Cuidado pré-natal. Paternidade. atenção primaria de saúde,.adesão.

ABSTRACT: Including the father figure in care relevant to the pregnancy cycle is a challenge, since it is seen as a maternal responsibility and few health services promote paternal integration. Pregnancy is a unique moment where the father's participation encourages the mother and develops and promotes the bond with the child from the womb. Given its importance to understand the reasons that promote the absence of parents in prenatal care will provide nurses with strategies to reverse this situation and to achieve these goals, the research was carried out through a systematic literature review, with 17 scientific articles being selected on the thematic research was carried out from April to November 202I.

Keywords: Prenatal care.paternity. primary health care.accession.

\footnotetext{
'Acadêmico de enfermagem Centro Universitário Redentor matheus_gutterres@hotmail.com ${ }^{2}$ Acadêmico de enfermagem Centro Universitário Redentor ribeiroserranojoaopedro@gmail.com

${ }^{3}$ Enfermeira no Centro de Atendimento Clínico de Itaperuna (CACI). Docente e orientadora na graduação de Enfermagem no Centro Universitário Redentor (UniREDENTOR) fabiola.apolinario@uniredentor.edu.br
} 


\section{INTRODUÇÃO}

A Lei Federal de n. 9.263, segundo o Art. $3^{\circ}$ de 12 de janeiro de 1996 Brasil (1996), assegura às gestantes o direito ao pré-natal, que se caracteriza como um acompanhamento especializado, onde serão realizados exames contínuos para assistir à saúde da mãe e do bebê. Nesse modo, o Ministério da Saúde (2006), afirma que a assistência ao pré-natal deve ocorrer mediante condutas acolhedoras para ambos os pais, com o objetivo de acarretar melhorias como a detecção precoce de doenças, atendimento ambulatorial básico, entre outros.

Em primeiro plano, consoante a Balica; Aguiar (2019), assim como as mães, os pais também precisam de cuidados que devem ser oferecidos pelos enfermeiros durante a assistência ao pré-natal. Nesse âmbito, a sociedade associa a gestação ao sexo feminino, porém é notório que a participação dos pais durante as consultas e as orientações se tornam de extrema importância para que eles possam compreender o que ocorre com a mulher durante a gestação e no estado puerperal, mas também para eles se integralizarem no ambiente familiar.

A gravidez é um momento único e que varia muito, pois cada mulher a significa de um modo, umas se tornam ainda mais fortes, enquanto outras ficam frágeis e inseguras. Nesse sentido, em ambos os casos a presença paterna é indispensável, haja vista que ele irá fortalecer a gestante, bem como criará desde a barriga um vínculo afetivo com seu filho. O distanciamento dos pais durante o acompanhamento gestacional é resultado de uma cultura machista, já que a paternidade acaba sendo vista somente como uma obrigação, onde o pai deve arcar com os gastos do filho e não como um direito que eles têm de participar ativamente em todas as etapas do desenvolvimento da criança que começa desde a concepção. (BALICA; AGUIAR; 20I9)

Partindo desse cenário, o presente artigo teve como objetivo geral analisar e apresentar estratégias para aumentar a incidência e permanência dos parceiros no acompanhamento dos cuidados pré-natais, para isso foi necessário a compreensão dos motivos que levam a defasagem dos pais durante o pré-natal. Proporcionando ao enfermeiro estratégias e intervenções para promover o aumento da adesão e permanência dos pais no acompanhamento gestacional e puerperal. 
Entende-se que seja necessário buscar a participação paterna para o acompanhamento do desenvolvimento do seu filho. Assim é imprescindível que haja um cuidado especial com a sua saúde. Desse modo, Costa; Taquette (2017), entende que o pré-natal masculino é um fenômeno que vai além da concepção, pois necessita de ações que envolvam o homem em todo o planejamento familiar até o puerpério, fortalecendo assim, o vínculo familiar.

Em muitos casos a ausência paterna deve-se a alguns fatores que impedem a sua participação, como por exemplo o horário das consultas que são realizadas no mesmo horário do trabalho. Assim, o enfermeiro pode desconstruir a perspectiva de que aquele momento é exclusivo da mãe e atrair o companheiro junto de suas parceiras para que possam juntos acompanhar todo o desenvolvimento do seu filho, proporcionando assim, um período de mais união e afeto na relação de pai e mãe diante da gestação. Nesse âmbito, Henz; Medeiros; Salvadori (2017), afirmam que no atual programa de pré-natal, a secretaria do serviço de saúde desenvolve atividades para as gestantes, o que dificulta a participação dos parceiros no processo de gestação. Para os profissionais isso é um desafio, pois é preciso mudar a perspectiva de cuidado que envolve a gestante e seu companheiro, onde ele possa adentrar com uma maior facilidade.

Dessa forma, a ausência dos pais durante o pré-natal acaba causando malefícios para o vínculo familiar. Assim, esse distanciamento paterno desencadeou estratégias e intervenções, que serão tratadas ao longo do artigo, com o intuito de fortalecer as relações familiares durante o período gestacional. É direito do pai participar do pré-natal, ser acolhido pela equipe de saúde, sendo ofertado um acolhimento de qualidade, zelando pelos seus direitos fundamentais. (SANTOS,2018)

\section{MATERIAIS E MÉTODOS}

O presente artigo trata-se de um estudo de revisão bibliográfica sistemática utilizando artigos que relatam sob a baixa adesão dos pais no ciclo gravídico puerperal, publicados no período de abril a novembro de 202I, sendo necessário a ampliação das datas de publicação visto a 
dificuldade de artigos nessa temática (1996;2004 a 2019). Nas plataformas de como Arca Fiocruz, Biblioteca Virtual de Saúde-Ministério da Saúde, Centro Científico conhecer, Revista de atenção à Saúde RAS, Revista Cogitare Enfermagem-ufpr, SciELO (Scientific Electronic Library Online), Portal de Periódicos CAPES/MEC e também analisamos em cadernos de atenção básica e também em leis voltada para a temática. Para tal, foram selecionadas palavras chaves para o levantamento do trabalho científico, incluindo: pré-natal, paternidade, atenção primária à saúde, adesão, tendo como resultado final 17 artigos com a temática, sendo excluído produções que não eram pertinentes ao objetivo da pesquisa e que não atendessem a questão norteadora, a seleção deu-se pela leitura dos resumos.

\section{RESULTADOS E DISCUSSÃO}

3.I Adesão paterna no pré-natal

Entende-se que é necessário a inclusão do pai durante todo o processo de pré-natal, de acordo com Mendes e Santos (2019) o vínculo das mulheres com o bebê ocorre desde o início da gestação fazendo com que ela se torne mãe durante esse processo, com isso a necessidade de promover o pré-natal masculino por meio de estratégias educativas voltadas para a participação paterna durante todo a gravidez. Ainda de acordo com Benazzi, Lima e Souza (20II) o estabelecimento do vínculo entre pai e o bebê pode ocorre ainda durante a gravidez quando o pai participa das consultas, assiste ultrassonografia, descobre o gênero do seu filho e compartilha com a mãe toda a experiência gestacional.

O enfermeiro tem o papel fundamental nesse processo de adesão e participação paterna durante todo o pré-natal, pois é o mesmo que vai ficará responsável pela desconstrução de todo o processo histórico cultural sendo o melhor momento para retirar a ideia de que essa experiência é única e exclusiva para mulheres e desenvolver dinâmicas envolvendo a participação do parceiro. (FERREIRA, et al 2014)

Dessa forma o profissional enfermeiro desempenha um papel de extrema importância na aceitação e acolhimento do pai na atenção básica e aproveita esse momento para criar vínculo 
entre o pai e a unidade, incentivando a participar das rotinas de pré-natal para considerar as preocupações e os sentimentos com a gravidez contribuindo para a autoestima do pai (Ferreira, 2016; Mendes, 2019).

Diante disso, o Ministério da Saúde com o objetivo de envolver os pais nos debates e ações para tornar o planejamento do parto uma estratégia básica e garantir a elegibilidade para a atenção ao nascimento, parto e gravidez. Desenvolveu o Pré-Natal do Parceiro por meio da Política Nacional de Atenção Integral à Saúde do Homem (PNAISH) (BRASIL, 2016). O guia contém várias orientações acerca de como deve ser o acolhimento e a evolução do pré-natal com o homem.

A criação do pré-natal masculino não tem só o objetivo de preparar o homem para o exercício da paternidade ativa, onde inclui esse pai em todo o processo de atividades educativas em relação ao pré-natal, mas também busca uma proximidade desse pai para a unidade básica de saúde mostrando a importância de uma medicina preventiva, onde busca fomentar nesse pai a ter hábitos saudáveis e também sobre prevenção de saúde tendo em vista que a população masculina em geral busca o atendimento médico já nos estágios avançados da doença (BRASIL,2016).

3.2 Benefícios da adesão do pai durante assistência pré-natal

É muito importante que o enfermeiro não deixe o pai em segundo plano durante as consultas de pré-natal, mostram para os pais que é importante sua participação pode contribuir para criação de um vínculo mais afetivo tanto com sua parceira quanto para o seu filho, mesmo que para essa participação seja necessária uma desconstrução histórica. O planejamento de reprodução e as ações de saúde são voltadas ao momento do parto, puerpério e gestação tudo isso é com o foco mãe e filho, deixando o pai em segundo plano (BRASIL,20I6). Sendo assim o profissional de saúde, mais especificamente o enfermeiro precisa desconstruir esse processo histórico sendo um desafio, já que, de acordo com Brasil (2016) os profissionais de saúde possuem dificuldades em atingir o público masculino por meio de ações que visem mobilizar a participação do pai no pré-natal. 
A inclusão paterna do pai no período gestacional vai além do financeiro, essa inclusão é fundamental para o entendimento da fase que sua parceira está passando, o que vai garantir o bem-estar psicossocial da mulher, proporcionando assim um período gestatório mais tranquilo para o neném e também o fortalecimento do vínculo pai e filho e consequentemente uma relação de trinômio, pai-mãe-filho mudando assim o antigo foco binômio mãe e bebê, garantindo assim um vínculo familiar desde a gestação. (BRASIL, 2016).

Entende-se que é de suma importância a participação paterna durante todo o processo gestacional, tanto para o fortalecimento do vínculo pai e filho antes mesmo do seu nascimento quanto para a relação da mulher com esse período gestacional, onde ela vai necessitar de um apoio maior devido a tantas mudanças inerentes ao ciclo gravídico puerperal, (CHUVA 2007) a participação paterna pode melhorar a qualidade de vida, autoestima, o autocuidado da gestante e como consequência disso é claro o benefícios de uma gestação tranquila e mais prazerosa não só para a mãe mas sim para a família.

Diante disso o Ministério da Saúde vem estimulando o pré-natal do parceiro desde 20II, para que esse possa fazer parte do processo gestacional, sentindo-se pai desde o pré-natal, já que, muitos homens acreditam que se tornam pais, apenas após o nascimento do bebê. Essa iniciativa estimula a paternidade responsável, cuidadora e responsável, aumentando o elo entre pai e filho. (VITORETTI, 202I).

Dessa forma é preciso que o enfermeiro durante o acompanhamento pré-natal busque desconstruir toda a questão cultural e incentivar que os pais participem de forma ativa de todo o processo gestacional, ainda segundo Brasil (2016), durante o pré-natal é necessário acolher a figura paterna, onde o profissional vai sanar as dúvidas e atrair esse indivíduo para as atividades educativas onde deve ser frisado sua importância diante da sua família.

Outro fator importante é o fato de os homens terem maior dificuldade em reconhecer suas necessidades de saúde, rejeitando a possibilidade de adoecer (COFEN, 2017). Isto faz com que acabem procurando o sistema de saúde através da assistência especializada, tendo como consequência o agravo das doenças, muitas vezes, pela demora no atendimento e isso reflete na 
conscientização da importância de sua participação na saúde da gestante e filho. (MINISTÉRIO DA SAÚDE, 2016).

Quadro I - Benefícios participação ciclo puerperal

\begin{tabular}{|c|c|c|c|c|}
\hline $\begin{array}{l}\text { Autor/ } \\
\text { Autores }\end{array}$ & Ano & Título do Artigo & Variável & Afirmação \\
\hline $\begin{array}{l}\text { Garlet et } \\
\text { al. }\end{array}$ & 2008 & $\begin{array}{l}\text { Percepção de gestantes } \\
\text { acerca da importância } \\
\text { do envolvimento } \\
\text { paterno nas consultas } \\
\text { pré-natal: um olhar de } \\
\text { gênero }\end{array}$ & $\begin{array}{l}\text { Fortalecimento do } \\
\text { vínculo familiar. }\end{array}$ & $\begin{array}{l}\text { 'O apoio do parceiro, ou seja, o } \\
\text { envolvimento com a gestação, indica o } \\
\text { comprometimento e o desejo de } \\
\text { estabelecer vínculo afetivo com a } \\
\text { criança. A mulher, apoiada por seu } \\
\text { companheiro, apresenta menos } \\
\text { sintomas físicos e emocionais, menos } \\
\text { complicações no trabalho de parto e } \\
\text { no parto, além de uma adaptação mais } \\
\text { fácil ao pós-parto." }\end{array}$ \\
\hline Chuva. & 2007 & $\begin{array}{l}\text { Apoio do pai do recém- } \\
\text { nascido durante a } \\
\text { gravidez percebido pela } \\
\text { mãe adolescente: fator } \\
\text { relevante para um pré- } \\
\quad \text { natal adequado? }\end{array}$ & $\begin{array}{c}\text { Melhora na } \\
\text { autoestima da mãe, } \\
\text { consequentemente } \\
\text { um período } \\
\text { gestacional tranquilo. }\end{array}$ & $\begin{array}{l}\text { "Os resultados encontrados sugerem } \\
\text { que o fato de sentir-se apoiada pelo pai } \\
\text { do recém-nascido influenciou atitudes } \\
\text { positivas na gestante, evitando o } \\
\text { consumo de cigarros e bebidas e a } \\
\text { optar por prosseguir a gravidez (...)." }\end{array}$ \\
\hline $\begin{array}{l}\text { Balica e } \\
\text { Aguiar. }\end{array}$ & 2019 & $\begin{array}{c}\text { Percepções Paternas no } \\
\text { acompanhamento do } \\
\text { pré-natal. }\end{array}$ & $\begin{array}{l}\text { O entendimento do } \\
\text { pai do momento de } \\
\text { sua parceira. }\end{array}$ & $\begin{array}{l}\text { 'A política de integralidade, pelo SUS, } \\
\text { é que, aos poucos, promove avanços } \\
\text { nessa situação, trazendo o pai para o } \\
\text { contexto gestacional, de forma que } \\
\text { possa vivenciar a chegada do filho e } \\
\text { também compreender o que acontece } \\
\text { com a sua companheira.' }\end{array}$ \\
\hline
\end{tabular}




\begin{tabular}{|c|c|c|c|c|}
\hline $\begin{array}{l}\text { Vitoretti } \\
\text { FM, et al. }\end{array}$ & 2021 & $\begin{array}{l}\text { O pré-natal do parceiro } \\
\text { sexual: importância } \\
\text { para a saúde do homem } \\
\text { e da gestante }\end{array}$ & $\begin{array}{l}\text { O fortalecimento da } \\
\text { relação pai-filho. }\end{array}$ & $\begin{array}{l}\text { "O Ministério da Saúde (MS) vem } \\
\text { estimulando o pré-natal do parceiro } \\
\text { desde 2oII, para que esse possa fazer } \\
\text { parte do processo gestacional, } \\
\text { sentindo-se pai desde o pré-natal. } \\
\text { Muitos homens acreditam que se } \\
\text { tornam pais, apenas após o } \\
\text { nascimento do bebê. Essa iniciativa } \\
\text { estimula a paternidade responsável, } \\
\text { Cuidadora e responsável, aumentando } \\
\text { o elo entre pai e filho (a)." }\end{array}$ \\
\hline $\begin{array}{l}\text { Vitoretti } \\
\text { FM, et al. }\end{array}$ & 2021 & $\begin{array}{l}\text { O pré-natal do parceiro } \\
\text { sexual: importância } \\
\text { para a saúde do homem } \\
\text { e da gestante }\end{array}$ & $\begin{array}{l}\text { Olhar holístico para } \\
\text { saúde paterna. }\end{array}$ & $\begin{array}{l}\text { "Outro fator importante é o fato de os } \\
\text { homens terem maior dificuldade em } \\
\text { reconhecer suas necessidades de } \\
\text { saúde, rejeitando a possibilidade de } \\
\text { adoecer. Isto faz com que acabem } \\
\text { procurando o sistema de saúde através } \\
\text { da assistência especializada, tendo } \\
\text { como consequência o agravo das } \\
\text { doenças, muitas vezes, pela demora no } \\
\text { atendimento." }\end{array}$ \\
\hline
\end{tabular}

3.3 Intervenção do profissional enfermeiro na promoção da participação do pai durante o ciclo gravídico puerperal

A educação em saúde é de suma importância para que possamos de fato atrair os pais para o acompanhamento do pré-natal e também para os cuidados da saúde do mesmo, já que os homens não costumam olhar para saúde de maneira preventiva sendo essencial a participação do enfermeiro no fortalecimento dessa assistência, pois o mesmo tem um contato direto com as famílias e sabe das condições e suas relações interdisciplinares. (BENIGNA; NASCIMENTO; MARTINS 2004)

A participação paterna ativa e o compromisso com a família são benéfica e influencia diretamente no desenvolvimento gestatório e além do mais é nesse momento que o enfermeiro deve aproveitar do comprometimento do pai durante o pré-natal para ensinar sobre os cuidados com a gestante e o bebê e orientá-los a respeito da gestação e em relação de planejamento familiar (Brasil,1998).

De acordo com Ferreira (2014), é necessário que o enfermeiro junto com toda equipe multidisciplinar presente no pré-natal entenda e reconheça a dificuldade enfrentadas pela gestante e seu companheiro durante esse período gestacional traçando estratégias para que possam ter uma gestação e 
um puerpério de qualidade. É necessário ter equidade para atender a todos com qualidade de maneira universal e para isso temos a necessidade de ter um olhar humano sobre a população.

Diante disso, é necessário reforçar que o Sistema Único de Saúde (SUS), garante o acompanhamento durante o pré-natal e também no parto (Brasil, 2016). Com isso o SUS não só garante o acompanhamento como também incentiva que os enfermeiros e toda equipe multidisciplinar possa incentivar que esse pai participe de todos os momentos do desenvolvimento do seu filho, garantindo um vínculo maior com seu filho e também uma gravidez mais saudável para a mãe do mesmo.

Quadro 2 - Estratégias e intervenções cabíveis ao enfermeiro

\begin{tabular}{|c|c|c|c|c|}
\hline $\begin{array}{l}\text { Autor/ } \\
\text { Autores }\end{array}$ & Ano & Título do Artigo & Variáveis & Afirmações \\
\hline $\begin{array}{l}\text { Ferreira,et } \\
\text { al. }\end{array}$ & 2016 & $\begin{array}{l}\text { Percepções de } \\
\text { gestantes acerca da } \\
\text { atuação dos parceiros } \\
\text { nas consultas de pré- } \\
\text { natal }\end{array}$ & $\begin{array}{l}\text { Educação } \quad \text { em } \\
\text { saúde. }\end{array}$ & $\begin{array}{l}\text { "Logo, é primordial que os } \\
\text { homens tenham facilidade de } \\
\text { acesso a esses serviços, sintam- } \\
\text { se acolhidos e motivados a } \\
\text { participar das consultas e de grupos } \\
\text { educativos, e apresentem } \\
\text { justificativas concretas para } \\
\text { incentivar que outros pais também } \\
\text { participem." }\end{array}$ \\
\hline $\begin{array}{l}\text { Balica, e } \\
\text { Aguiar. }\end{array}$ & 2019. & $\begin{array}{l}\text { Percepções Paternas } \\
\text { no acompanhamento } \\
\text { do pré-natal. }\end{array}$ & $\begin{array}{l}\text { Acolhimento e } \\
\text { inserção desse } \\
\text { pai no período } \\
\text { gestacional. }\end{array}$ & $\begin{array}{l}\text { "A ausência do pai no pré- } \\
\text { natal, parto e puerpério também } \\
\text { resulta de políticas de saúde que } \\
\text { privilegiam o atendimento } \\
\text { apenas para aquela que é } \\
\text { diretamente a usuária, nesse caso, a } \\
\text { gestante." }\end{array}$ \\
\hline $\begin{array}{l}\text { Ferreira, } \\
\text { et al. }\end{array}$ & 2016 & $\begin{array}{l}\text { Percepções de } \\
\text { gestantes acerca da } \\
\text { atuação dos parceiros } \\
\text { nas consultas de pré- } \\
\text { natal. }\end{array}$ & $\begin{array}{l}\text { Mostra a } \\
\text { importância da } \\
\text { inclusão paterna } \\
\text { durante o período } \\
\text { gestacional. }\end{array}$ & $\begin{array}{l}\text { "A inserção do homem em espaços } \\
\text { destinados à compreensão de si e } \\
\text { dos outros, de novos papéis sociais, } \\
\text { como aqueles que dizem respeito ao } \\
\text { ser mãe e ao ser pai, apresenta } \\
\text { influência positiva nas suas } \\
\text { experiências, principalmente no } \\
\text { que diz respeito a uma vivência } \\
\text { mais consciente e plena de seus } \\
\text { papéis." }\end{array}$ \\
\hline
\end{tabular}


3.4 Dificuldades enfrentadas pelo pai para o efetivo engajamento no cuidado pré-natal

Entende-se que seja de uma cultura machista e de uma visão antiga onde o homem deveria se importar somente com a parte financeira da estrutura familiar e todo o resto era deixado de lado e com isso a necessidade do enfermeiro promover estratégias que visão essa desconstrução dessa cultura. São inúmeros os fatores que influenciam ou dificultam a não participação dos pais na consulta de pré-natal, entre elas estão: coincidência com o horário de trabalho, falta de tempo, desinteresse, falta de informações, não reconhecimento da paternidade, limites pessoais e institucionais, a inexistência de serviços destinados aos homens e até mesmo algumas a falta de uma educação em saúde que faz com as mulheres inconscientemente não permita que seus companheiros possam atuar nesse momento.( MENDES e DOS SANTOS, 2019)

São inúmeros os fatos que levam esse distanciamento paterno do acompanhamento gestacional, cabe ao profissional de saúde inserirem esses pais no processo gestacional, pois o mesmo, muitas das vezes não tiveram uma referência durante sua vida e por conta desse processo cultural acabam se fazendo também pai ausente (BRASIL,2016). Ainda de acordo com esse processo cultural podemos citar em relação a própria legislação em respeito à diferença horária entre a licença maternidade e licença paternidade, fazendo uma diferenciação de gênero e dificultando também essa participação paterna no processo gestacional. (COSTA et al, 2017)

Importante destacar o desinteresse por parte do pai que por uma questão cultural ou até mesmo pela falta de entendimento sobre seus direitos não compreende que pode acompanhar sua parceira nesse momento e nem mesmo tem ciência que temos todo um projeto voltado para a saúde do homem e também voltado para família. De acordo com Costas e Taquette, a gestação é um fenômeno que vai além do trabalho de parto e a participação paterna é necessária, pois ele está inserido em todo o ciclo sexual e reprodutivo, com isso entendemos a necessidade de incluir esse pai no durante todo o pré-natal e também incluir esses pais no planejamento familiar.

Portanto, ressalta-se que é necessário estimular os pais a participarem de todas as etapas da gestação e do pré-natal, levando em consideração a importância dessa participação para o bem-estar da mãe, de si mesmo e do bebê, para que os homens possam sentir-se parte do processo de gravidez, e ajudar a fortalecer vínculos afetivos saudáveis entre ele, sua companheira e os filhos (BRASIL, 2016; HENZ et al., 2017).

\section{Quadro 3 - Dificuldade para adesão ao pré-natal pelos pais}




\begin{tabular}{|c|c|c|c|c|}
\hline $\begin{array}{l}\text { Autor/ } \\
\text { Autores }\end{array}$ & Ano & Título do Artigo & Variável & Afirmação \\
\hline $\begin{array}{l}\text { Balica e } \\
\text { Aguiar. }\end{array}$ & 2019 & $\begin{array}{c}\text { Percepções Paternas } \\
\text { no acompanhamento } \\
\text { do pré-natal. }\end{array}$ & Cultural/machismo. & $\begin{array}{c}\text { 'Contudo, culturalmente, a } \\
\text { paternidade só se inicia } \\
\text { com o nascimento.' }\end{array}$ \\
\hline $\begin{array}{c}\text { Albuquerque, } \\
\text { et al. }\end{array}$ & 2014 & $\begin{array}{c}\text { O homem na } \\
\text { atenção básica: } \\
\text { percepções de } \\
\text { enfermeiros sobre as } \\
\text { implicações do } \\
\text { gênero na saúde. }\end{array}$ & $\begin{array}{c}\text { Absenteísmo no } \\
\text { trabalho. }\end{array}$ & $\begin{array}{l}\text { Portanto, a ausência do } \\
\text { homem nos serviços de } \\
\text { saúde é também justificada, } \\
\text { no discurso masculino, pela } \\
\text { incompatibilidade entre os } \\
\text { horários de trabalho e o de } \\
\text { funcionamento das } \\
\text { unidades }\end{array}$ \\
\hline $\begin{array}{c}\text { Costa e } \\
\text { Taquette. }\end{array}$ & 2017 & $\begin{array}{l}\text { Atenção à gestante } \\
\text { adolescente na rede } \\
\text { SUS - o } \\
\text { acolhimento do } \\
\text { parceiro no pré- } \\
\text { natal. }\end{array}$ & Desinteresse. & $\begin{array}{l}\text { 'Por outro lado, o } \\
\text { desconhecimento do direito } \\
\text { de participar se encaixa no } \\
\text { modelo hegemônico de } \\
\text { gênero em que o homem } \\
\text { não exerce nenhum } \\
\text { protagonismo na gestação } \\
\text { de seu filho e também } \\
\text { tradicionalmente não } \\
\text { procura o serviço de saúde a } \\
\text { não ser quando doente.' }\end{array}$ \\
\hline $\begin{array}{l}\text { Balica e } \\
\text { Aguiar. }\end{array}$ & 2019 & $\begin{array}{l}\text { Percepções Paternas } \\
\text { no acompanhamento } \\
\text { do pré-natal. }\end{array}$ & $\begin{array}{l}\text { Falta de acolhimento } \\
\text { dos pais acerca de } \\
\text { políticas voltada para } \\
\text { saúde do homem. }\end{array}$ & $\begin{array}{l}\text { O Ministério da Saúde } \\
\text { incluiu-o oficialmente no } \\
\text { pré-natal, no contexto da } \\
\text { Política Nacional de } \\
\text { Atenção Integral à Saúde } \\
\text { do Homem (PNAISH), } \\
\text { por meio da Portaria } \\
\text { GM/MS n. 1.944, de } 27 \text { de } \\
\text { agosto de 2009. }\end{array}$ \\
\hline
\end{tabular}




\section{${ }_{4}$ CONCLUSÃO}

Com a produção dos estudos foi possível compreender que o cuidado pré-natal é um momento de suma importância onde a figura paterna deve ser inserida ativamente e de forma permanente. Apesar do Ministério da Saúde ter criado o pré-natal do parceiro é necessário avançarmos no uso de tecnologias leves em saúde como educação em saúde, grupo de pais, acolhimento, vínculo com a unidade para que a Política Nacional de Atenção Integrada à Saúde do homem, seja conhecida e caminhe juntamente com as políticas de saúde da Mulher, garantido aos pais (pai e mãe) uma abordagem à saúde de forma holística especialmente referente aos homens que tendem em cuidar de sua saúde. A educação em saúde é a maior estratégia do enfermeiro quanto a promoção da adesão do pai nos cuidados pré-natal sendo a implementação de rodas de conversa/grupos, que é uma ferramenta barata e de simples execução que proporcionará ao pai um ambiente seguro e acolhedor para troca de saberes integrando o pai ao processo gestacional fortificando sua paternidade.

\section{REFERÊNCIAS}

ALBUQUERQUE GA, LEITE MF, BELÉ JM, NUNES JFC, OLIVEIRA MA, ADAM F. O homem na atenção básica: percepções de enfermeiros sobre as implicações do gênero na saúde. Esc Anna Nery. [Internet] 2014 [citado 2018 Set 24]; 18 (4): 607-6r4. Disponível em:〈https://www.scielo.br/j/ean/a/7JLPvVtNBXPhzbDrWvjqTWJ/?lang=pt $>$. Acesso em: 24 maio de 202I.

BALICA, LUCIANA OLIVEIRA; AGUIAR, RICARDO SARAIVAS. Percepções Paternas no acompanhamento do pré-natal. Rev. Aten. Saúde, São Caetano do Sul, v. I7, n. 6I, p. II4-I26, jul./set., 2019. Disponível em: https://seer.uscs.edu.br/index.php/ revista_ciencias_saude/article/view/5934/pdf.>. Acesso em: or de maio de 2021.

BENAZZI, A.S.T; LIMA, A.B.S; SOUSA, A.P. Pré-natal masculino: um novo olhar sobre a presença do homem. $\quad$ BA, 20II. Disponível em: $\langle$ http://www.periodicoseletronicos.ufma.br/index.php/rppublica/article/view/849/871. . Acesso em: 26 out. 2021.

BENIGNA, MARIA JOSÉ CARIRI; NASCIMENTO, WEZILA GONÇALVES; MARTINS, JOÂNIO LOPES. Pré-natal no programa saúde da família: com a palavra os enfermeiros. Cogitare Enferm., Curitiba, v.9, n. 2, p. 23-31, 2004. Disponível em: $\langle$ https://revistas.ufpr.br/cogitare/article/view/1713〉.Acesso em: 02 de jun de 2021. 
BRASIL. Lei. 9.263, de I2 de janeiro de 1996. Trata do planejamento familiar, estabelece penalidades e dá outras providências. Diário Oficial da União, Brasília, DF, is jan. 1996. Disponível em: http://www.planalto.gov.br/ccivil_03/leis/19263.htm. Acesso em: I6 mai. 2021.

BRASIL. Ministério da Saúde. Assistência pré-natal: normas e manuais técnicos.DF, 1998.Disponível em: 〈https://bvsms.saude.gov.br/bvs/publicacoes/pre_natal.pdf >. Acesso em: 28 de out. 202I.

BRASIL. MINISTÉRIO DA SAÚDE. Secretaria de Atenção à Saúde. Departamento de Ações Programáticas Estratégicas. Coordenação Nacional de Saúde do Homem. Guia do pré-natal do parceiro para profissionais de saúde. Rio de Janeiro; Ministério da Saúde; 2016. 55 p. Disponível em: 〈http://portalarquivos.saude.gov.br/images/pdf/ 2016/agosto/II/guia_PreNatal.pdf >. Acesso em: 25 de maio 2021.

CHUVA, V.C.C. Apoio do pai do recém-nascido durante a gravidez percebido pela mãe adolescente: fator relevante para um pré-natal adequado? RJ, 2007. Disponível em:

〈https://www.arca.fiocruz.br/bitstream/icict/4768/2/907.pdf >. Acesso em: 26 out 2021.

COSTA, S. F.; TAQUETTE, S. R. Atenção à gestante adolescente na rede SUS - o acolhimento do parceiro no pré-natal. Revista de Enfermagem UFPE online. v. II(Supl. 5), p. 2067-74, 2017. Disponível em: 〈https://periodicos.ufpe.br /revistas/revistaenfermagem/article/viewFile/23360/18984>.Acesso em: 24 mai. 2021.

FERREIRA, I.S et al. Percepções de gestantes acerca da atuação dos parceiros nas consultas de pré-natal. CE, 2016. Disponível em: 〈http://www.periodicos.ufc.br/rene/article/view/3444/268o〉. Acesso em: 26 out. 202I.

FERREIRA, T.N et al. A importância da participação paterna durante o pré-natal: Percepção da gestante e do pai no município de Cáceres-MT. MT, 2014. Disponível em: 〈https://periodicos.unb.br/index.php/rgs/article/view/432/415〉. Acesso em: 26 out. 2021.

FREITAS WMF, et al. Paternidade: responsabilidade social do homem no papel de provedor. Rev Saúde Pública. 2009; 43(I):85-90. Disponível em: $<\quad$ https://www.scielo.br/

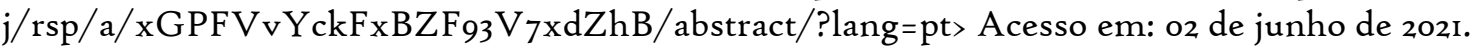

HENZ, G. S.; MEDEIROS, C. R. G.; SALVADORI, M. A inclusão paterna durante o pré-natal. Revista de Enfermagem e Atenção à Saúde. v. 6, n. I, p. 52-66, 2017. Disponível em:

$\langle$ https://www.univates.br/bdu/bitstream/10737/1732/r/2016GabrielaSofiaHenz.pdf $\rangle$.Acesso em: 24 mai. 2021.

MENDES, S.C; DOS SANTOS, K.C.B. Pré-natal masculino: a importância da participação do pai nas consultas de pré-natal. MA, 2019. Disponível em: <https://www.conhecer.org.br/enciclop/2019a/sau/pre\%2onatal.pdf. $>$ Acesso em: 26 out. 202I.

MINISTÉRIO DA SAÚDE. Pré-natal e puerpério: atenção qualificada e humanizada. Manual Técnico. Brasília: Ministério da Saúde; 2006. (Série A. Normas e Manuais Técnicos; Série Direitos 
Sexuais e Direitos Reprodutivos - Caderno 5). Disponível em: $\langle$ https://bvsms.saude.gov.br/bvs/publicacoes/manual_pre_natal_puerperio_zed.pdf $\rangle$.Acesso em: 4 mai. 2021.

SANTOS, MÁBIA LOURRANE PEREIRA. A importância do pai no pré-natal e a atuação do enfermeiro de uma unidade básica de saúde. Faculdade João Pinheiro-MG. João Pinheiro, dez. 2018. Disponível em: 〈http://tcc.fcjp.edu.br:8o8o/pdf/oo8722〉.pdf Acesso em: I6 mai. 2021.

SHAKESPEARE, WILIAM.O MERCADOR DE VENEZA. Disponível em: $\langle$ http://www.dominiopublico.gov.br/download/texto/cvoooo94.pdf $\rangle$. Acesso em: I2 nov. 202I.

PESAMOSCA, LUCÉLIA GARLET; FONSECA, ADRIANA DORA DA; GOMES, VERA LÚCIA DE OLIVEIRA. Percepção de gestantes acerca da importância do envolvimento paterno nas consultas pré-natal: um olhar de gênero. Revista Mineira de Enfermagem., MG, 2008. Disponível em: 〈https://www.reme.org.br/artigo/detalhes/255\#>. Acesso em: 28 out. 202I

VITORETTI, F.M et al. O pré-natal do parceiro sexual: importância para a saúde do homem e da gestante. $M G, \quad$ 2021. $\quad$ Disponível $\quad$ em: <https://acervomais.com.br/index.php/saude/article/view/5470/3513 >. Acesso em: 28 out. 202I. 